\title{
G scustem \\ The Influence of Family Support During Endoscopic Submucosal Dissection (ESD) on Patient's Anxiety
}

\section{Ruo-yu Gao}

Shenzhen People's Hospital, Second Clinical Medical College of Jinan University

Ri-Yun Gan

Shenzhen People's Hospital, Second Clinical Medical College of Jinan University

Jia-Lan Huang

Shenzhen People's Hospital, Second Clinical Medical College of Jinan University

Ting-Ting Liu

Shenzhen People's Hospital, Second Clinical Medical College of Jinan University

\section{Ben-Hua Wu}

Shenzhen People's Hospital, Second Clinical Medical College of Jinan University

\section{Li-Sheng Wang}

Shenzhen People's Hospital, Second Clinical Medical College of Jinan University

\section{De-Feng Li}

Shenzhen People's Hospital, Second Clinical Medical College of Jinan University Jun Yao ( $\nabla$ yj_1108@126.com )

Shenzhen People's Hospital, Second Clinical Medical College of Jinan University

\section{Research Article}

Keywords: Depression, Anxiety, Endoscopic submucosal dissection (ESD), Complications

Posted Date: September 9th, 2021

DOl: https://doi.org/10.21203/rs.3.rs-691890/v1

License: (c) (1) This work is licensed under a Creative Commons Attribution 4.0 International License.

Read Full License 


\section{Abstract}

Background: Psychological problems, such as anxiety and depression, may promote peptic ulcers. The influence of family support on the healing of gastric endoscopic mucosal dissection (ESD)-induced ulcers remains largely undetermined.

Objective: In the present study, we aimed to assess the Hospital Anxiety and Depression Scale (HADS) scores and the incidence of post-ESD complications in patients with family support in the care process and those in the non-relative group.

Materials and Methods: A total of 191 patients aged between 30 and 70 years who received gastric ESD were evaluated with the Chinese version of HADS. Differences in depression and anxiety between the two groups were compared using the chi-square test and t-test. Multivariable logistic regression models were used to examine whether anxiety and depression were the risk factors for post-ESD complications.

Results: The mean values of HADS-A ( $4.61 \pm 2.89$ vs. $5.56 \pm 3.07, p=0.042)$ and HADS-D $(4.14 \pm 3.03$ vs. $4.97 \pm 2.61, p=0.048$ ) scores were significantly lower in patients with accompanying relatives compared with those in the non-relative group. Besides, through the pre-ESD and post-ESD self-contrast, the scores of anxiety and depression in the relative-group were 0.57 and 0.56 , respectively $(p<0.001)$, while those in the non-relative group were increased by 1.43 and 1.49 , respectively $(p<0.001)$. Multivariable logistic regression analysis revealed that HADS-A, HADS-D scores, and age were significantly correlated with post-ESD complications $(p<0.05)$.

Conclusions: The occurrence and degree of psychological anxiety and depression in patients who received gastric ESD with accompanying relatives during hospitalization were reduced, and the incidence of post-ESD complications was also decreased.

\section{Introduction}

Upper gastrointestinal cancers are the most common leading causes of cancer mortality worldwide [1], accounting for $13.7 \%$ of all cancer-related deaths [2]. Every year, about 1.5 million people are diagnosed with gastric or esophageal cancers [3,4] posing tremendous challenges to the healthcare system due to their aggressive presentation [5]. As a new minimally invasive technique, endoscopic mucosal dissection (ESD) is used to treat gastrointestinal (GI) superficial neoplasias [6, 7]. ESD is a technically complex process, and it removes a large area of the mucosa that may increase the risk of adverse events, such as pain, bleeding, and perforation [8-10]. Delayed bleeding is the most important adverse event associated with ESD [10]. Since patients may have fear of the operation, apprehension about their illness, and the ESD may cause some pain and discomfort, they are prone to psychological anxiety and depression during the perioperative period.

Health anxiety or depression is a common problem in the community [11], which imposes a huge burden on health services [12]. Studies have shown that certain inflammatory diseases are associated with bad 
mood. Inflammation caused by anxiety and depression is the most common reason for GI mucosal injury [13]. Its damage to the GI mucosa may involve a variety of different psychophysiological mechanisms, from stress stimulation of thyroid-stimulating hormone (TSH, a peptic ulcer promoter) [14] to local blood flow changes [15], leading to damage to the gastric mucosal barrier.

Peptic ulcer belongs to the category of typical psychosomatic diseases, and psycho-social factors play an important role in its pathogenesis [16]. In recent years, psychological intervention can significantly reduce the degree of anxiety and depression, resulting in enhanced quality of life of patients [17]. Family support is one of the important ways of psychological intervention, which can bring mental security to patients. Therefore, the production of negative emotions can be reduced accordingly, and family support plays an important role in the healing of GI mucosal injury $[18,19]$.

Patients planning to receive gastric ESD may experience psychological distress. Up to date, no study has evaluated the impacts of relatives on anxiety, depression, and complications in patients receiving gastric ESD. In the present study, we aimed to assess the prevalence of anxiety, depression, and ESD complications in patients.

The Hospital Anxiety and Depression Scale (HADS) is a commonly used self-assessment scale to assess the psychological distress in non-psychiatric patients. The HADS questionnaire has been translated into many languages and applied in different countries and regions $[20,21]$. The rating of the HADS scale is shown in Table 1 [22].

\section{Patients And Methods}

\section{Patients}

A total of 220 patients who underwent their first gastric ESD at the Shenzhen People's Hospital from August 2020 to February 2021 were enrolled in this study. The patients were divided into the relative group and non-relative group according to whether they were accompanied by relatives or not during the perioperative period. During the perioperative period, patients looked after by relatives were set up as the relative group ( $\mathrm{n}=92)$, and those looked after by non-relatives (hired caregivers) were set up as the nonrelative group $(n=89)$. After the detailed screening, 29 patients were excluded from this study. The procedure and results of screening, as well as the patient classification, were shown in the flowchart (Fig. 1). In the relative group, there were 43 males and 49 females aged 30-70, with an average age of $51.9 \pm$ 9.1 years. In terms of disease type, there were four cases of high-grade intraepithelial neoplasia (HGIN), 74 cases of low-grade intraepithelial neoplasia (LGIN), one case of atrophic gastritis, three cases of superficial gastritis, and 10 cases of raised lesions. In the non-relative group, there were 48 males and 41 females aged 30-69, with an average age of $50.1 \pm 7.5$ years. In terms of disease type, there were three cases of HGIN, 73 cases of LGIN, four cases of superficial gastritis, and nine cases of raised lesions. The inclusion criteria were set as follows: (1) 18-80 years old; (2) diagnosed with early GI tumors or raised lesions; and (3) receiving ESD treatment and willing to provide informed consent. The exclusion criteria 
were as follows: (1) patients with severe systemic diseases, including kidney, liver, or heart dysfunction; (2) patients with a previous history of anxiety/depression or admission anxiety/depression score $\geq 8$; and (3) patients with Mallory-Weiss syndrome, post-gastrectomy, and coagulation dysfunction. The general data on age, sex, and type of disease between the two groups were not significantly different ( $p>$ 0.05) (Table 2). The study was approved by the Ethics Committee of Shenzhen people's Hospital (approval No. of the ethic committee: KY-LL-2020114-01) and registered at ClinicalTrials.gov with the identifier ChiCTR2000032851.

\section{Methods}

On the following day of admission, all patients were informed of the purpose and procedures of the study. If patients were willing to participate, they were asked to sign an informed consent form. Trained researchers recorded demographic and baseline clinical characteristics of each patient and then assisted the patients to perform the test using the Chinese version of the HADS. Additionally, in the family section of the survey, basic demographic information was collected on the closest family member who accompanied the patient more in the course of hospitalization. Both groups of patients underwent gastric ESD. The patients in the non-relative group were given the routine procedure as follows: the doctor introduced the surgical method to the patient and relieved the patient's tension before the operation. Postoperative proton-pump inhibitor (PPI) therapy can promote the healing of ESD-induced ulcers and reduce the risk of bleeding and abdominal pain. For the relative-group, besides the above-mentioned routine procedures, the accompanying family members were informed to communicate more with the patient, patiently listen to the patient's ideas and concerns, encourage the patient to relax, and provide the patient with a warm, quiet, and comfortable environment. After the surgery, the researchers recorded the HADS scores (the 3rd day after operation) and postoperative complications of both groups.

\section{Measures}

The severity of the patient's anxiety and depression was scored with the HADS [23]. HADS is a self-report questionnaire consisting of 14 items, including seven items assessing anxiety (HADS-A) and the other seven items assessing depression (HADS-D). The total score of each subscale obtained ranges from 0 to 21 (higher scores indicate higher anxiety/depression level). In the present study, the demarcation point of 8 was used to diagnose anxiety and depression [20,24]. The HADS-A1 and HADS-D1 were defined as the anxiety and depression subscales of HADS for the relative group, respectively. HADS-A2 and HADS-D2 were defined as the anxiety and depression subscales of HADS for the non-relative group, respectively.

\section{Statistical Analysis}

All data were statistically analyzed using R software (Version 3.5.3). Continuous variables were expressed as means and standard deviations (SD) and compared using the t-test. Categorical data were 
expressed as percentages and compared using the chi-square test. Normal distribution was assessed by the Kolmogorov-Smirnov test. The independent-samples t-test was used for normally distributed continuous variables. and the Mann-Whitney U-test was used for non-normally distributed continuous variables. Multivariate logistic regression analysis was performed to determine the impact of the factors on postoperative ESD complications. The regression model included the following factors: age, gender, anxiety, depression, pylori infection, type of lesion, and lesion location. Variables reaching significance, or borderline significance, on univariate analysis $(p<0.1)$ were subsequently incorporated into a multivariate model. In all tests, a $p$ value $<0.05$ was considered statistically significant.

\section{Result}

\section{Study Population}

A total of 180 patients with GI neoplasia and 30 patients with gastric raised lesions were enrolled in our cohort. Among these patients, 24 patients meeting the exclusion criteria and five patients with serious complications during gastric ESD were excluded. Therefore, there were 162 patients with GI neoplasia and 19 patients with a gastric raised lesion in the final analysis. The surgical specimens of each patient were finally diagnosed by pathology (Figure 1). Table 2 lists the demographic and clinical characteristics of the patients.

\section{Comparison between groups: Difference in HADS scores}

The anxiety and depression scores of all patients included in this study were $\leq 7$ before gastric ESD. The baseline of HADS-A (4.04 \pm 2.34 vs. $4.13 \pm 2.13, p=0.927)$ and HADS-D $(3.58 \pm 2.47$ vs. $3.48 \pm 2.02, p=0.801)$ scores was similar between the two groups (Table 3). Figure 2 shows the distribution of differences. However, in terms of postoperative scores, the mean values of HADS-A ( $4.61 \pm 2.89$ vs. $5.56 \pm 3.07$, $p=0.042)$ and HADS-D ( $4.14 \pm 3.03$ vs. $4.97 \pm 2.61, p=0.048)$ scores were significantly lower in the relative group compared with the non-relative group (Table 3 ).

\section{Self-contrast: Difference in HADS scores between pre-ESD and post-ESD}

Besides, through the pre-ESD and post-ESD self-contrast, the scores of anxiety and depression in the relative group were 0.57 and 0.56 , respectively $(p<0.001)$, while those in the non-relative group were increased by 1.43 and 1.49, respectively $(p<0.001)$ (Table 4$)$. Figure 3 and Figure 4 illustrate the distribution of differences.

\section{Risk of complications following gastric ESD}


After gastric ESD, we observed two types of complications as follows: abdominal pain and bleeding. Table 5 shows the scores of HADS and the incidence of complications in each group. Apparently, the incidence of abdominal pain in the non-relative group was significantly higher compared with the relative group ( $19.1 \%$ vs. $8.7 \%, p=0.04)$. However, there was no significant difference in the incidence of bleeding between the two groups. We conducted multivariate logistic regression analysis for the complications. The results showed that HADS-A scores $\geq 8(\mathrm{OR}, 3.016 ; 95 \% \mathrm{Cl}, 1.111-8.118, \mathrm{p}=0.0303)$, HADS-D scores $\geq 8(\mathrm{OR}, 3.143 ; 95 \% \mathrm{Cl}, 1.035-9.547, \mathrm{p}=0.043)$ and individuals aged $<50$ years $(\mathrm{OR}, 0.296 ; 95 \% \mathrm{Cl}$, $0.104-0.839, p=0.022$ ) were significantly associated with post-ESD complications. Other factors, such as sex, $\mathrm{H}$. pylori infection, type of lesion, and lesion location, were not associated with post-ESD complications ( $p>0.05$, Figure 5).

\section{Discussion}

As one of the most studied areas of psychosomatic diseases, the relationship between negative emotions and peptic ulcers has been intensively investigated $[25,26]$. Similarly, negative emotions can also affect the healing of iatrogenic ulcers caused by gastric ESD. Overall, the prevalence of psychological distress in this study was about $19 \%$, which was relatively lower compared with previous studies on patients with gastric lesions in other countries $[27,28]$. Such discrepancy might be attributed to the fact that the included patients in previous studies are diagnosed with different stages of gastric cancer before evaluation. Instead, we recruited only patients with dysplasia and raised lesions. Besides, on the following day of admission, patients with an abnormal value of HADS scores were excluded.

When patients know that they need to do gastric ESD, they may be prone to psychological disorders during the perioperative period due to apprehension about unknown diseases and fear of surgery. In our observational study, we found that the HADS scores of all patients were increased in varying degrees. However, such an increase in patients in the non-relative group was more obvious. Besides, we found that the average anxiety and depression scores of the relative group were lower compared with the nonrelative group $(p<0.05)$. This finding indicated that for hospitalized patients, the accompanying of relatives could reduce the occurrence and degree of anxiety and depression to a certain extent. They could help patients with psychological counseling. Therefore, the patients could maintain a relatively positive and optimistic attitude, leading to reduced impact of psychological factors on the disease. Some studies have shown that the occurrence of bad emotions is negatively correlated with family support[29, 30].

Routine administration of PPI can suppress gastric acid secretion and promote ulcer healing after ESD, resulting in retarded development of post-ESD bleeding [31,32]. In terms of complications after gastric ESD, we found six cases of bleeding and 25 cases of abdominal pain. Relatively speaking, patients in the non-relative group were more likely to undergo complications $(p<0.05)$. By multivariate logistic regression analysis, we found that the ESD complications showed a positive correlation with all subscales of HADS scores and age, while they were not associated with lesion location, type, H. pylori infection, and gender. In conclusion, the relative group had a lower HADS score and a lower incidence of 
post-ESD complications. During the perioperative period, we should try our best to persuade family members to take care of patients, especially elderly patients. Through strengthening humanistic care, the production of bad emotions could be reduced to promote the healing of ESD-induced ulcers.

This observational study has several obvious limitations. First, this was a single-center cross-sectional study with a relatively small sample size, which might limit the reliability of the results. Second, patients with a previous history of mental disorders and an admission HADS score $\geq 8$ were excluded. Therefore, the impact on these patients remained unknown. Third, instead of classifying patients based on the type and location of gastric lesions, we evaluated all patients together.

\section{Conclusion}

Our study revealed that patients receiving gastric ESD under the care of relatives during hospitalization had lower HADS-A and HADS-D scores compared with the non-relative group. Besides, the incidence of post-ESD complications in the relative group was significantly lower compared with the non-relative group. These findings suggested that patients receiving gastric ESD who were accompanied by their families were more conducive to emotional stability, showing less postoperative clinical manifestations.

\section{Declarations}

\section{Ethics approval and consent to participate}

The study was approved by the Ethics Committee of Shenzhen people's Hospital (approval No. KY-LL-2020114-01) and registered at ClinicalTrials.gov with the identifier ChiCTR2000032851. The patient provided both written and verbal consent to participate in this manuscript. This research was conducted in accordance with the stipulations of the Declaration of Helsinki for experiments involving humans.

\section{Consent for publication}

Patients involved in this case were consented for publication.

\section{Availability of data and material}

The datasets used and/or analyzed during the current study are available from the corresponding author on reasonable request.

\section{Competing interests}

The authors declare that they have no competing interests. 


\section{Funding}

Not applicable.

\section{Authors' contributions}

Gao RY, Gan RY and Huang JL prepared the tables and drafted the manuscript; Wu BH and Liu TT reviewed the manuscript for its intellectual content; Wang LS, Li DF and Yao J were responsible for revising the manuscript; all authors have read and approved the final manuscript.

\section{Acknowledgements}

Not applicable.

\section{References}

1. Siegel, R.L., K.D. Miller, and A. Jemal. Cancer statistics, 2018. CA Cancer J Clin, 2018. 68(1): p. 7-30 [PMID: 29313949 DOI: 10.3322/caac.21442]

2. Ferlay J, Soerjomataram I, Dikshit R, Eser S, Mathers C, Rebelo M, Parkin DM, Forman D, Bray F. Cancer incidence and mortality worldwide: sources, methods and major patterns in GLOBOCAN 2012. Int J Cancer, 2015. 136(5): p. E359-86 [PMID: 25220842 DOI: 10.1002/ijc.29210]

3. Zhang, Y. Epidemiology of esophageal cancer. World J Gastroenterol, 2013. 19(34): p. 5598 - 606 [PMID: 24039351 DOI: 10.3748/wjg.v19.i34.5598]

4. Pasechnikov V, Chukov S, Fedorov E, Kikuste I, Leja M. Gastric cancer: prevention, screening and early diagnosis. World J Gastroenterol, 2014. 20(38): p. 13842-62 [PMID: 25320521 DOI:

10.3748/wjg.v20.i38.13842]

5. Otutaha B, Srinivasa S, Koea J. Patient information needs in upper gastrointestinal cancer: what patients and their families want to know. ANZ J Surg, 2019. 89(1-2): p. 20-24 [PMID: 29893038 DOI: 10.1111/ans.14565]

6. Pimentel-Nunes P, Dinis-Ribeiro M, Ponchon T, Repici A, Vieth M, De Ceglie A, Amato A, Berr F, Bhandari P, Bialek A, Conio M, Haringsma J, Langner C, Meisner S, Messmann H, Morino M, Neuhaus H, Piessevaux H, Rugge M, Saunders BP, Robaszkiewicz M, Seewald S, Kashin S, Dumonceau JM, Hassan C, Deprez PH. Endoscopic submucosal dissection: European Society of Gastrointestinal Endoscopy (ESGE) Guideline. Endoscopy, 2015. 47(9): p. 829 - 54 [PMID: 26317585 DOI: 10.1055/s0034-1392882]

7. Odagiri $\mathrm{H}$, Yasunaga $\mathrm{H}$. Complications following endoscopic submucosal dissection for gastric, esophageal, and colorectal cancer: a review of studies based on nationwide large-scale databases. Ann Transl Med, 2017. 5(8): p. 189 [PMID:28616404 DOI: 10.21037/atm.2017.02.12] 
8. Chung IK, Lee JH, Lee SH, Kim SJ, Cho JY, Cho WY, Hwangbo Y, Keum BR, Park JJ, Chun HJ, Kim HJ, Kim JJ, Ji SR, Seol SY. Therapeutic outcomes in 1000 cases of endoscopic submucosal dissection for early gastric neoplasms: Korean ESD Study Group multicenter study. Gastrointest Endosc, 2009. 69(7): p. 1228-35 [PMID: 19249769 DOI: 10.1016/j.gie.2008.09.027]

9. Miyahara K, Iwakiri R, Shimoda R, Sakata Y, Fujise T, Shiraishi R, Yamaguchi K, Watanabe A, Yamaguchi D, Higuchi T, Tominaga N, Ogata S, Tsuruoka N, Noda T, Hidaka H, Mannen K, Endo H, Yamanouchi K, Yamazato T, Sakata H, Fujimoto K. Perforation and postoperative bleeding of endoscopic submucosal dissection in gastric tumors: analysis of 1190 lesions in low- and highvolume centers in Saga, Japan. Digestion, 2012. 86(3): p. 273 - 80 [PMID: 22986899 DOI: 10.1159/000341422]

10. Choi CW, Kim HW, Kang DH, Hong YM, Kim SJ, Park SB, Cho M, Kim DJ, Hong JB. Clinical outcomes of second-look endoscopy after gastric endoscopic submucosal dissection: predictive factors with high risks of bleeding. Surg Endosc, 2014. 28(7): p. 2213-20 [PMID: 24570014 DOI: 10.1007/s00464014-3457-2]

11. Sunderland M, Newby JM, Andrews G. Health anxiety in Australia: prevalence, comorbidity, disability and service use. Br J Psychiatry, 2013. 202(1): p. 56-61 [PMID: 22500013 DOI: 10.1192/bjp.bp.111.103960]

12. Barsky AJ, Orav EJ, Bates DW. Somatization increases medical utilization and costs independent of psychiatric and medical comorbidity. Arch Gen Psychiatry, 2005. 62(8): p. 903 - 10 [PMID: 16061768 DOI: 10.1001/archpsyc.62.8.903]

13. Hernandez, D.E., Neurobiology of brain-gut interactions. Implications for ulcer disease. Dig Dis Sci, 1989. 34(12): p. 1809-16 [PMID: 2574655 DOI: 10.1007/bf01536696]

14. Kauffman, G.L., Stress, the brain, and the gastric mucosa. Am J Surg, 1997. 174(3): p. 271-5 [PMID: 9324135 DOI: 10.1016/s0002-9610(97)00134-7]

15. Livingston EH, Garrick TR, Scremin OU, Yasue N, Passaro EP, Guth PH. Heterogeneous distribution of gastric mucosal blood flow with restraint stress in the rat. Dig Dis Sci, 1993. 38(7): p. 1233-42 [PMID: 8325184 DOI: 10.1007/bf01296072]

16. Hernandez, D.E., D. Arandia, and M. Dehesa, Role of psychosomatic factors in peptic ulcer disease. J Physiol Paris, 1993. 87(4): p. 223-7 [PMID: DOI: 10.1016/0928-4257(93)90009-i]

17. Cape J, Whittington C, Buszewicz M, Wallace P, Underwood L. Brief psychological therapies for anxiety and depression in primary care: meta-analysis and meta-regression. BMC Med, 2010. 8: p. 38 [PMID: 20579335 DOI: 10.1186/1741-7015-8-38]

18. Levenstein, S., The very model of a modern etiology: a biopsychosocial view of peptic ulcer. Psychosom Med, 2000. 62(2): p. 176 - 85 [PMID: 10772394 DOI: 10.1097/00006842-20000300000003]

19. Kellner, R., Psychotherapy in psychosomatic disorders. Arch Gen Psychiatry, 1975. 32(8): p. 1021-8 [PMID: 1156110 DOI: 10.1001/archpsyc.1975.01760260085007] 
20. Bjelland I, Dahl AA, Haug TT, Neckelmann D. The validity of the Hospital Anxiety and Depression Scale. An updated literature review. J Psychosom Res, 2002. 52(2): p. 69-77 [PMID: 11832252 DOI: 10.1016/s0022-3999(01)00296-3]

21. Montazeri A, Vahdaninia M, Ebrahimi M, Jarvandi S. The Hospital Anxiety and Depression Scale (HADS): translation and validation study of the Iranian version. Health Qual Life Outcomes, 2003. 1: p. 14 [PMID: 12816545 DOI: 10.1186/1477-7525-1-14]

22. Stern, A.F., The hospital anxiety and depression scale. Occup Med (Lond), 2014. 64(5): p. 393-4 [PMID: 25005549 DOI: 10.1093/occmed/kqu024]

23. Zigmond, A.S. and R.P. Snaith, The hospital anxiety and depression scale. Acta Psychiatr Scand, 1983. 67(6): p. 361 - 70 [PMID: 6880820 DOI: 10.1111/j.1600-0447.1983.tb09716.x]

24. Reda, A.A., Reliability and validity of the Ethiopian version of the hospital anxiety and depression scale (HADS) in HIV infected patients. PLoS One, 2011. 6(1): p. e16049 [PMID: 21283565 DOI: 10.1371/journal.pone.0016049]

25. Kim SY, Min C, Oh DJ, Choi HG. Reciprocal association between depression and peptic ulcers: Two longitudinal follow-up studies using a national sample cohort. Sci Rep, 2020. 10(1): p. 1749 [PMID: 32020020 DOI: 10.1038/s41598-020-58783-0]

26. Levenstein S, Ackerman S, Kiecolt-Glaser JK, Dubois A. Stress and peptic ulcer disease. JAMA, 1999. 281(1): p. 10 - 1 [PMID: 9892430 DOI: 10.1001/jama.281.1.10]

27. Lee S, Oh ST, Lee H, Lee JS, Pak H, Choi WJ, Jeon HH. Associated risk factors for psychological distress in patients with gastric epithelial neoplasm undergoing endoscopic submucosal dissection. Medicine (Baltimore), 2018. 97(52): p. e13912 [PMID: 30593210 DOI:

10.1097/MD.0000000000013912]

28. Kim GM, Kim SJ, Song SK, Kim HR, Kang BD, Noh SH, Chung HC, Kim KR, Rha SY. Prevalence and prognostic implications of psychological distress in patients with gastric cancer. BMC Cancer, 2017. 17(1): p. 283 [PMID: 28427439 DOI: 10.1186/s12885-017-3260-2]

29. Bratis D, Tselebis A, Sikaras C, Moulou A, Giotakis K, Zoumakis E, Ilias I. Alexithymia and its association with burnout, depression and family support among Greek nursing staff. Hum Resour Health, 2009. 7: p. 72 [PMID: 19671188 DOI: 10.1186/1478-4491-7-72]

30. Keykha R, Rezaee N, Navidian A, Moshtaghi E. The Effect of Regular Family Appointments on Hope of Hospitalized Depressed Patients: a Randomized Clinical Trial. J Caring Sci, 2020. 9(1): p. 27-32 [PMID: 32296656 DOI: 10.34172/jcs.2020.005]

31. Ye BD, Cheon JH, Choi KD, Kim SG, Kim JS, Jung HC, Song IS. Omeprazole may be superior to famotidine in the management of iatrogenic ulcer after endoscopic mucosal resection: a prospective randomized controlled trial. Aliment Pharmacol Ther, 2006. 24(5): p. 837 - 43 [PMID: 16918888 DOI: 10.1111/j.1365-2036.2006.03050.x]

32. Yang Z, Wu Q, Liu Z, Wu K, Fan D. Proton pump inhibitors versus histamine-2-receptor antagonists for the management of iatrogenic gastric ulcer after endoscopic mucosal resection or endoscopic 
submucosal dissection: a meta-analysis of randomized trials. Digestion, 2011. 84(4): p. 315 - 20 [PMID: 22075541 DOI: 10.1159/000331138]

\section{Tables}

Due to technical limitations, tables are only available as a download in the Supplemental Files section.

\section{Figures}




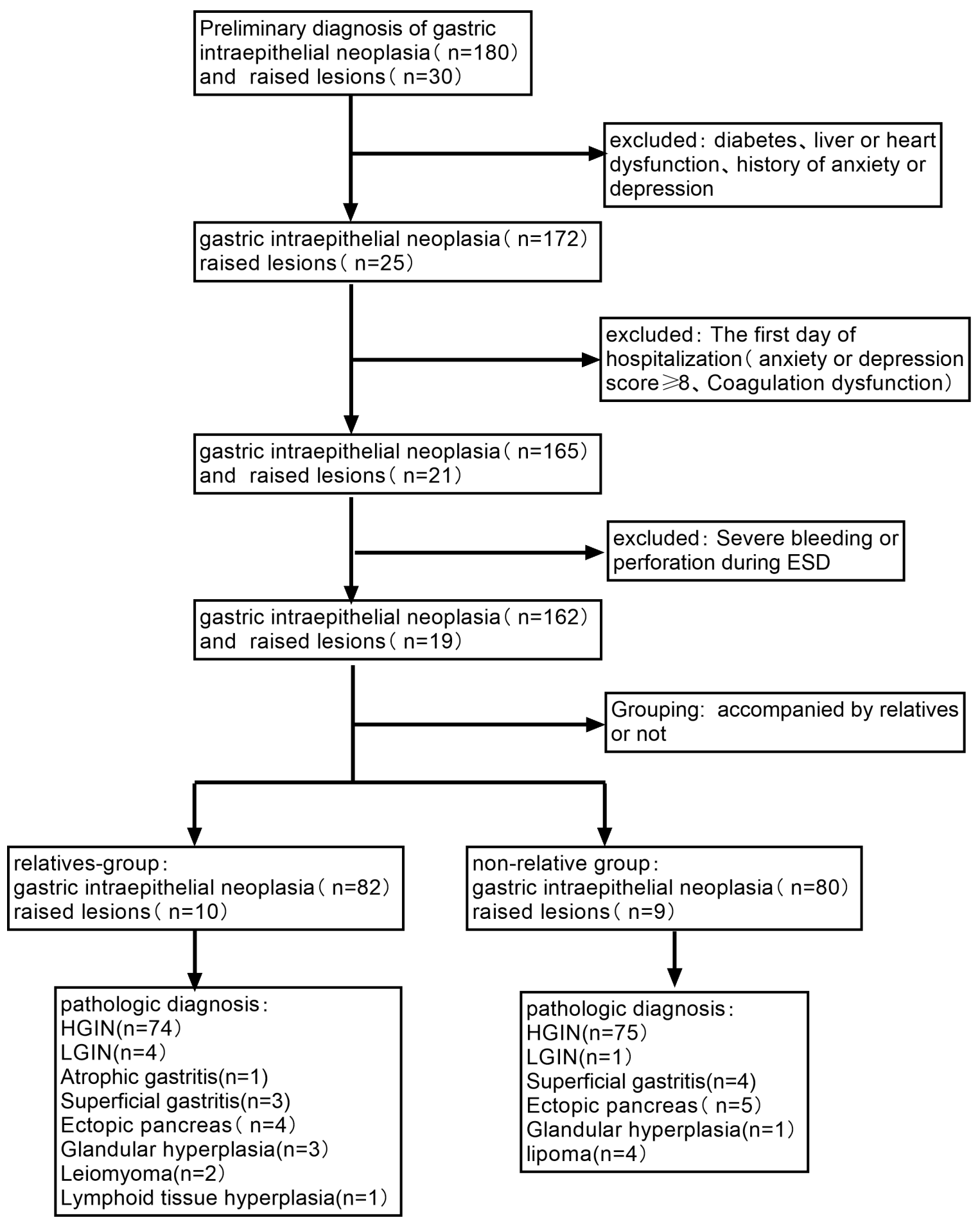

Figure 1. Flowchart demonstrating development of relatives-group and non-relative group

\section{Figure 1}

Please See image above for figure legend. 


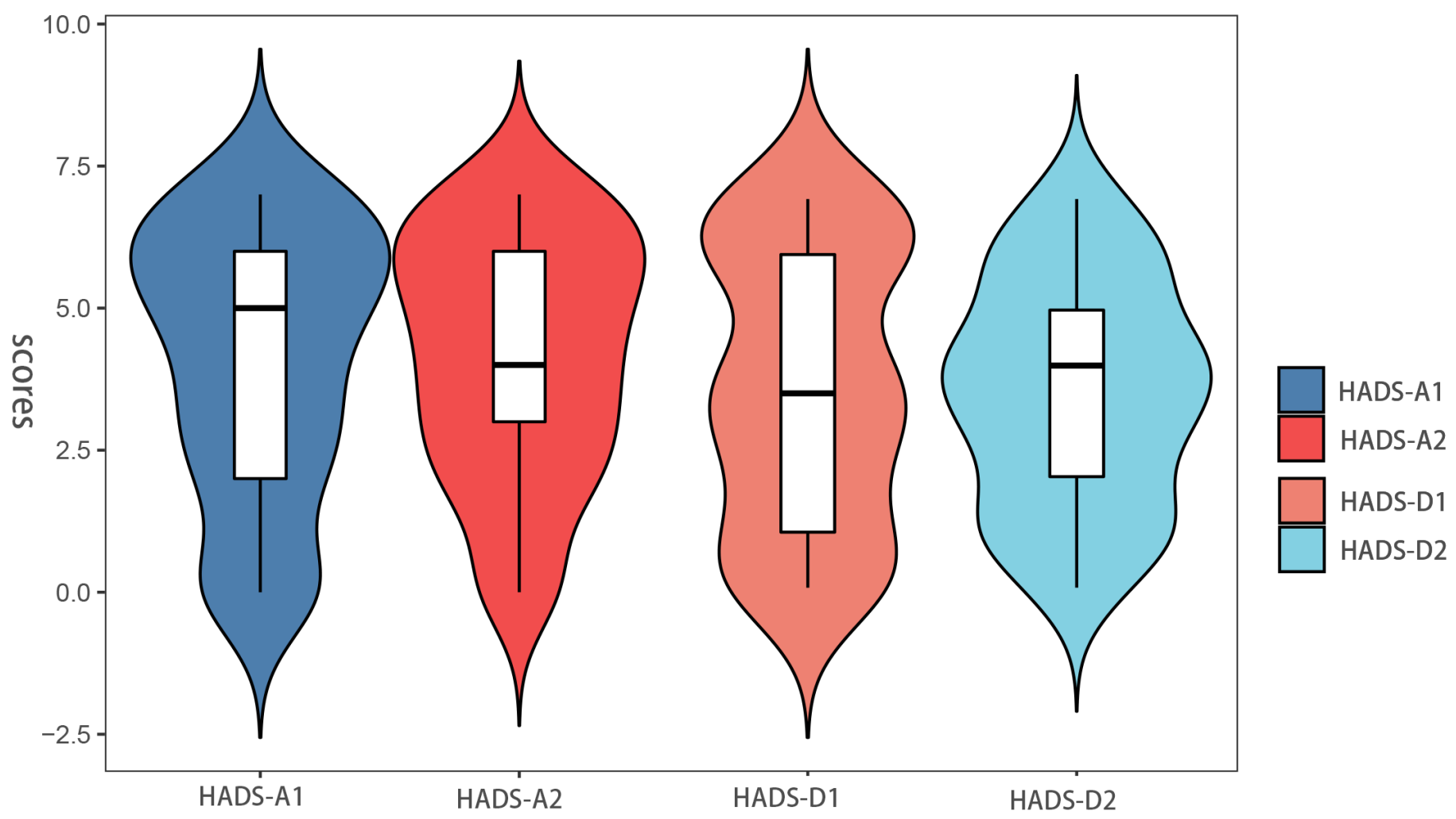

Figure2. Anxiety and depression scores between Pre-ESD of the patient in the relative and non-relative groups

Figure 2

Please See image above for figure legend. 


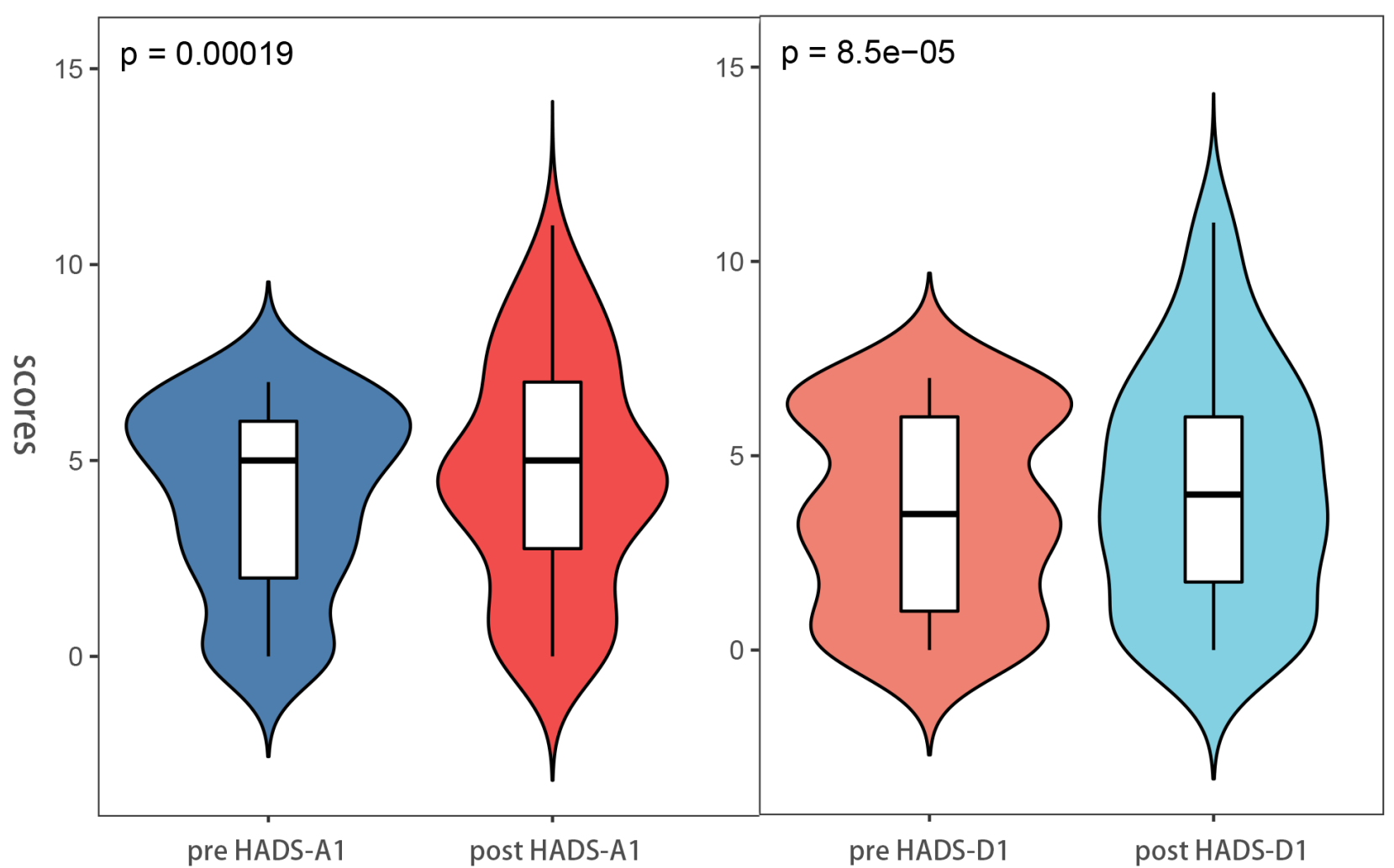

Figure3. anxiety and depression scores between Post-ESD and Pre-ESD of the patient in the relatives groups

Figure 3

Please See image above for figure legend. 


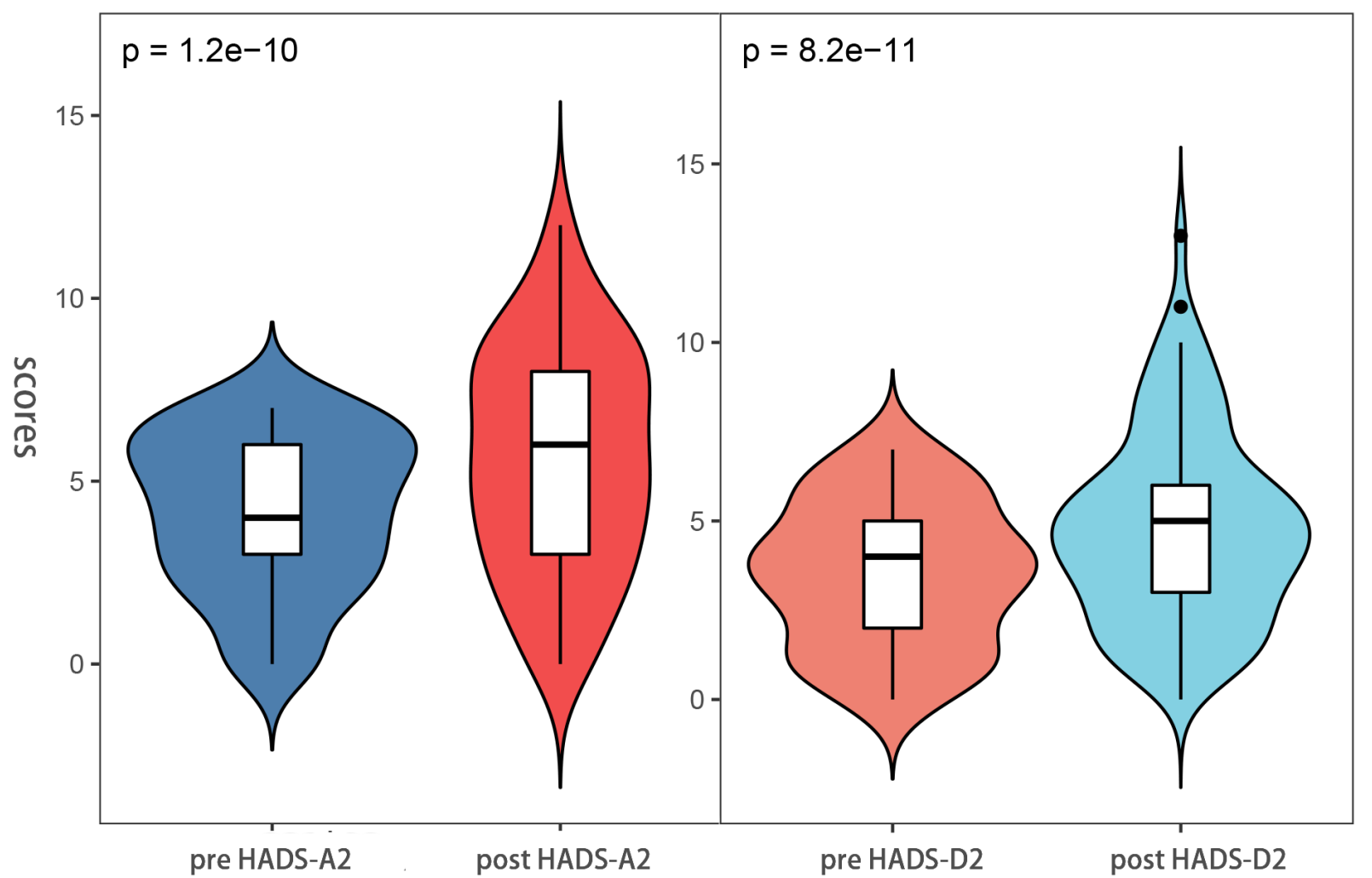

Figure4. anxiety and depression scores between Pre-ESD and Post-ESD of the patient in the non-relative groups

Figure 4

Please See image above for figure legend. 


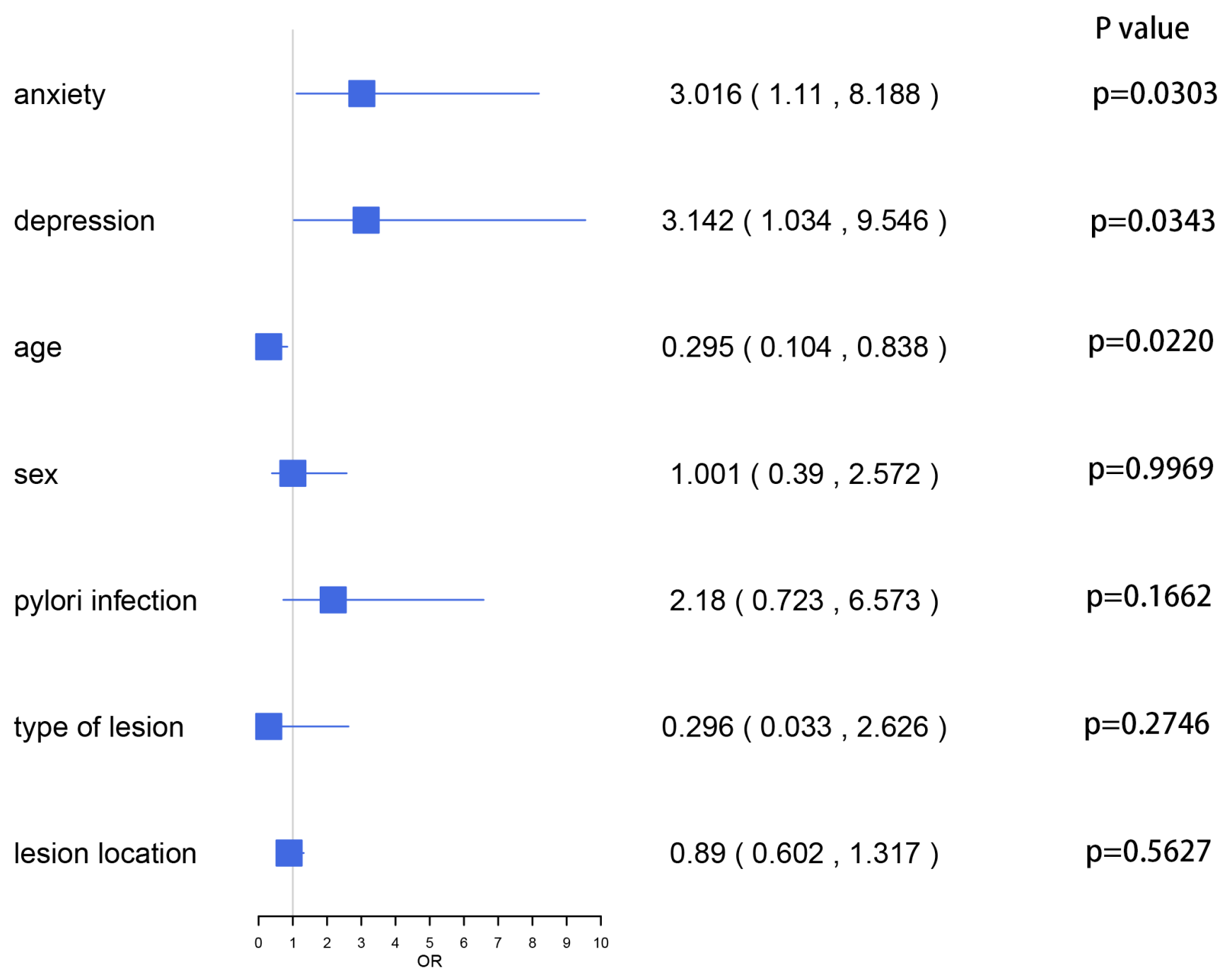

Figure 5.logistic regression analysis

Figure 5

Please See image above for figure legend.

\section{Supplementary Files}

This is a list of supplementary files associated with this preprint. Click to download.

- table1.tiff

- table2.tiff

- table3.tiff

- table4.tiff

- table5.tiff 